Editorial

\section{Acute mountain sickness}

The lure of the mountains draws more and more people to the Himalayas and Andes each year. Climbing expeditions proliferate but it is the trekking industry that has seen a veritable explosion of numbers in the last 12 years, especially in Nepal. Most find the experience of hiking through the grandest mountain scenery in the world rewarding, both mentally and physically. Unfortunately, some have their holidays blighted by illnesses, the most common of which are intestinal infections. But acute mountain sickness accounts for an appreciable morbidity amongst trekkers and in this issue the paper by Dickinson and others ( $p$ 646) reminds us of the potentially fatal nature of this condition. Acute mountain sickness is also a problem for residents of high altitude areas returning home, especially in South America, where residents of Cerro de Pasco $(4300 \mathrm{~m})$, for instance, can return from Lima (sea level) by road in a few hours. It is also a problem for construction and mining companies undertaking projects at high altitude and needing to send workmen up rapidly after periods of leave.

The common, mild form of acute mountain sickness, sometimes called simple or, better, benign acute mountain sickness, ${ }^{1}$ is well known and occurs in almost half of those undertaking the popular trek to Everest Base Camp. ${ }^{2}$ It was very well described by Ravenhill in $1913 .^{3}$ It consists of some or all of the following symptoms: headache, nausea, anorexia, vomiting, insomnia, poor climbing performance. As the epithet benign implies, provided that the hypoxic stress is not increased by climbing to a higher altitude the condition is self limiting, usually lasting two to three days. These symptoms are, however, to be regarded as a warning sign that further ascent is ill advised because of the possible development of one of the malignant forms of acute mountain sickness - that is, pulmonary (acute pulmonary oedema of high altitude) or cerebral (cerebral oedema of high altitude), or a mixture of the two. The onset of pulmonary acute mountain sickness is indicated by the development of breathless-

Address for reprint requests: Dr J Milledge, Division of Anaesthesia, Medical Research Council Clinical Research Centre, Watford Road, Harrow, Middx HA1 3UJ. ness and tachypnoea even at rest, with a dry cough at first and then one productive of white, frothy sputum and later sometimes of blood tinged sputum. Cerebral acute mountain sickness is characterised by one or more of the following featurés: ataxia, irritability and irrational behaviour, hallucinations, drowsiness, coma. Papilloedema may be found.

These forms of acute mountain sickness may be lethal in a few hours and demand urgent treatment (see below). It is with these forms, especially the cerebral form, that Dickinson and his coworkers are concerned in their paper in this issue. But these patients, it must be emphasised, represent a highly selected group out of a total population of patients with acute mountain sickness.

\section{Incidence}

The incidence of acute mountain sickness obviously depends on the rate at which people ascend to altitude and the height reached, as well as the exact definition of the condition. Hackett and Rennie ${ }^{2}$ found an overall incidence of $43 \%$ in trekkers reaching the aid post at Pheriche $(4243 \mathrm{~m})$, though some affected trekkers would have dropped out before reaching this height. Among those who flew into the airstrip at $2800 \mathrm{~m}$ the incidence was higher than among those who walked all the way ( $49 \%$ versus $31 \%)$. Among lowlanders who drive directly from Lima to Cerro de Pasco (4300 m) there are very few who do not have at least mild symptoms on the morning àfter arrival.

It is also difficult to be precise about the incidence of malignant acute mountain sickness. In their earlier paper $r^{4}$ Hackett and Rennie reported seven cases of pulmonary and five cases of cerebral acute mountain sickness in 278 trekkers (of whom 53\% had benign acute mountain sickness)-an incidence of $2.5 \%$ and $1.8 \%$. Menon ${ }^{5}$ found an incidence of $0.57 \%$ for acute pulmonary oedema in Indian troops flown to the modest altitude of $3500 \mathrm{~m}$ and Hultgien and Marticorena ${ }^{6}$ reported an incidence of $0.6 \%$ in adults coming to La Oroya $(3750 \mathrm{~m})$. The incidence will be influenced by the education of trekkers and there is a strong impression among workers at Pheriche that in recent years there has been a fall in the incidence of these malignant forms of acute mountain sickness as a result of health education by the Himalayan Rescue Association and others. Trekking companies are now well aware of the danger of letting their clients go on higher with symptoms, though private groups-especially, it seems, from the Alpine countries of Europe, are still inclined to treat the Himalayan altitudes with scant respect. 


\section{Aetiology}

Acute mountain sickness has a multifactorial aetiology; what are the risk factors? Probably the most important single factor is rapid ascent. Given a sufficiently rapid ascent to a high enough altitude, acute mountain sickness can be induced in almost everyone, while even the poorest acclimatiser can reach at least the intermediate altitudes given enough time. But within a given ascent profile such as a standard trek there is a large individual variation in susceptibility. In general, individuals respond consistently, so that performance on one occasion is a reliable guide to future performances, with a tendency to acclimatise better on each subsequent trip to altitude. Case histories do, however, show some anomalies. For instance, someone who has had little trouble on the first two trips may develop pulmonary oedema on a third. Possibly a respiratory infection may be the added factor in such cases. Sex is not important in the incidence of acute mountain sickness, though more men than women go to high altitudes and so more men will get it. The young are probably at greater risk than the old ${ }^{4}$ and the risk among boys seems especially high in South America. ${ }^{6}$ Beyond these factors, there is increasing evidence that subjects with a low ventilatory response to hypoxia are liable to develop acute mountain sickness. The association has been shown most convincingly in measurements of the response to acute hypoxia in the laboratory ${ }^{78}$ but it is also indicated by the reduction in alveolar carbon dioxide tension on arrival at altitude ${ }^{910}$ and from measurements of ventilation at high altitude. " $\mathrm{A}$ brisk increase in pulmonary arterial pressure in response to hypoxia is probably also a risk factor, ${ }^{12}$ but it cannot be consistently predicted by a 10 minute hypoxic laboratory test-and clearly such tests with cardiac catheterisation are not acceptable. Another response to hypoxia which varies between individuals is the reduction in angiotensin converting enzyme activity. We speculated that this might be protective and that people with a small response might be susceptible to acute mountain sickness. ${ }^{13}$

Exercise on arrival at high altitudes is a feature ot many case histories of pulmonary oedema, from the first English report (published by Houston in $1960^{14}$ ), and the high altitude residents in South America take the precaution of avoiding any exertion for a few days after coming back from sea level. ${ }^{3}$ Similar advice is given to Indian troops on arrival at altitude. Pulmonary oedema can, however, develop in the absence of exercise. ${ }^{5}$ So far as benign acute mountain sickness is concerned, the impression of mountaineers is that activity hastens recovery and certainly voluntary hyperventilation helps. Evidence that physical fitness helps to prevent acute mountain sickness is lacking. Indeed, many very fit people get into difficulties, possibly because they are more active and less inclined to slow down with early mild symptoms.

\section{Mechanisms}

What are the mechanisms of acute mountain sickness? Hypoxia is clearly the initiating factor but it is not the direct cause of the symptoms, since within a few minutes of exposure to actual or simulated high altitude $\mathrm{PO}_{2}$ falls throughout the body but symptoms of acute mountain sickness are delayed for at least a few hours. This suggests that hypoxia initiates some process which requires a time course of six to 12 hours before it in turn causes the symptoms.

The most popular suggestion is that hypoxia causes some alteration of fluid or electrolyte homeostasis with either water retention or shifts of water from intracellular to extracellular compartments, or both. This in turn results in the dependent and periorbital oedema often seen in patients with acute mountain sickness ${ }^{2}$ and in mild cerebral oedema causing the symptoms of the benign condition. More severe cerebral oedema causes malignant cerebral acute mountain sickness and pulmonary oedema causes the pulmonary form. Evidence of fluid retention is provided by the clinical observation of lower urine output in soldiers with acute mountain sickness than in soldiers free of symptoms, ${ }^{15}$ and by the finding that trekkers with the condition gained weight while trekkers without acute mountain sickness had lost weight by the time they reached $4243 \mathrm{~m}^{11}$. The "normal" response to altitude seems to be a mild diuresis whereas subjects destined to get acute mountain sickness have an antidiuresis, but we need more data here. The antidiuretic hormone (vasopressin) might be thought to underlie this mechanism but that seems not to be the case. Hackett et al ${ }^{16}$ did find raised levels of the hormone in cases of pulmonary oedema but not in benign acute mountain sickness, and it was argued that when vasopressin levels were raised this was probably the result rather than the cause of malignant acute mountain sickness. Harber $e t a^{17}$ found no rise in vasopressin levels in their climbers with acute mountain sickness, who included one with fatal cerebral oedema.

We have shown that the sort of exercise associated with trekking, when this follows a semisedentary life style, results in appreciable sodium retention and expansion of the extracellular fluid volume at the expense of the intracellular fluid volume. This may result in overt clinical oedema of the 
face and ankles. ${ }^{18}$ We later showed that this was due to activation of the renin aldosterone system. ${ }^{19} \mathrm{~A}$ review of 11 studies of the effect of altitude on renin and aldosterone in the absence of exercise showed that aldosterone concentrations have been found to fall in all studies but that renin activity may be reduced or unchanged or may rise. ${ }^{20}$ When we studied the combined effects of ascent to altitude and exercise resembling trekking we found very great rises in renin activity-to 8 times control levels, compared with an increase to 2-3 times control levels observed during similar exercise at sea level. Aldosterone concentrations were, however, similar to those found with exercise at sea level and therefore the aldosterone response to renin appeared to be blunted on going to altitude. This we attributed to the reduction in angiotensin converting enzyme activity, in turn a result of hypoxia. ${ }^{1321}$ Although the high level of renin activity associated with exercise did not result in equivalent high levels of angiotensin II and aldosterone, we speculated that the angiotensin converting enzyme response to hypoxia might be poor in susceptible subjects. In such individuals angiotensin converting enzyme activity would not fall much and they would have greatly raised angiotensin II and aldosterone levels. This would result in considerable sodium retention, increase in extracellular fluid volume, and a pressor response in both systemic and pulmonary circulations which would put them at greater risk of acute mountain sickness. Preliminary (unpublished) observations on the angiotensin converting enzyme response to acute hypoxia in good and poor acclimatisers seem to support this hypothesis.

Apart from these mechanisms affecting total body fluid compartments, local mechanisms are undoubtedly important in producing cerebral and pulmonary oedema. The cerebral circulation is exquisitely sensitive to changes in arterial oxygen and carbon dioxide tension. In those going to high altitude hypoxia will tend to cause vasodilatation while hypocarbia will tend to cause vasoconstriction. People with acute mountain sickness tend to be more hypoxic and have a higher $\mathrm{PCO}_{2}$ than those without symptoms. ${ }^{10}$ Possibly their greater cerebral vasodilatation contributes to their symptoms and the development of cerebral oedema.

The pathophysiology of the acute pulmonary oedema of high altitude has been the subject of much debate. The clinical picture is similar to that of left ventricular failure but, although it is hard to rule this out entirely, the evidence from catheter studies is that the pulmonary wedge pressure ${ }^{22} 23$ and (on the basis of one patient, with a patent foramen ovale) left atrial pressure are normal. ${ }^{24}$ In all cases, however, the pulmonary artery pressure is greatly increased. There is not space in this article to discuss the various suggested mechanisms in detail. They are not mutually exclusive and include an increase in capillary permeability as a direct result of hypoxia or via mediators whose concentrations are increased by hypoxia; a non-uniform vasoconstriction resulting in torrential flow in less constricted areas, leading to oedema in these areas ${ }^{12} 25$; and fluid leakage through arterial walls proximal to the resistance vessels. ${ }^{26}$ There is some suggestive evidence for all these possibilities. For instance, the association of proteinuria with acute mountain sickness ${ }^{2728}$ supports the idea of increased permeability of blood vessels. The other two suggested mechanisms would explain the highly non-uniform appearance of this form of pulmonary oedema as seen on chest radiographs and at necropsy, where some areas of the lung are found to be perfectly normal, some oedematous, and some frankly haemorrhagic.

Finally, in both lung and brain a primary derangement in the clotting mechanism resulting in thrombosis must be considered as a possible underlying mechanism. In reports of necropsy material, including the paper of Dickinson and his colleagues in this issue, the presence of thrombosis in lungs and brain figures prominently. No doubt parts of the pathological picture are secondary, such as the development of hyaline membrane in the alveoli and possibly some thrombi, but there is evidence of alterations in coagulation associated with altitude $\mathrm{e}^{29}$ and thrombosis may form a basis for the development of both pulmonary hypertension and oedema, as discussed in Dickinson's paper and more fully in a book by Heath and Williams. ${ }^{30}$ Hyers and coworkers ${ }^{10}$ were, however, unable to show differences in activated coagulation between those who are susceptible to pulmonary oedema and normal individuals at altitude.

\section{Management}

\section{PROPHYLAXIS}

To avoid acute mountain sickness the aphorisms are "Hasten slowly" and "Climb high, sleep low." The crucial altitude is that at which the night is spent and a suggested rule of thumb is that above $3000 \mathrm{~m}$ each night should be spent not more than $300 \mathrm{~m}$ above the last, with a rest day-that is, two nights at the same altitude-every two or three days. The problem in recommending any given rate of ascent is that susceptibility varies so much that what is safe for most is unduly cautious for good acclimatisers and too rapid for poor acclimatisers. So an addition to this advice is that anyone who has symptoms of acute mountain sickness should go no higher until they improve. The logistics of a trekking holiday, 
however, often demand a more rapid height gain at times and, with the goal of the holiday of a lifetime almost within reach, people are reluctant to be cautious.

People who know that they are poor acclimatisers but wish to enjoy the high mountains without being a drag on their companions may ask for help to do so. In these circumstances it is now justified to recommend prophylaxis with acetazolamide. This drug has been shown to increase $\mathrm{PaO}_{2}$ and decrease $\mathrm{PaCO}_{2}{ }^{31}$ and to reduce the incidence of acute mountain sickness in several well conducted double blind trials. ${ }^{42-34}$ The only side effect reported is that of paraesthesia, which tends to diminish with time but is present in most people. The mechanisms for the beneficial effects are thought to be as follows. Acetazolamide is an inhibitor of carbonic anhydrase; thus it interferes with transport of carbon dioxide out of cells. This results in an intracellular acidosis that includes the cells of the medullary chemoreceptor (and peripheral chemoreceptors). It also promotes the renal excretion of bicarbonate, thus countering the usual respiratory alkalosis. There is therefore stimulation of respiration so that the newcomer to high altitude is in effect artificially acclimatised. $\mathrm{PaO}_{2}$ is improved not only by day but also when the person is asleep, ${ }^{35}$ when hypoxaemia can otherwise be profound during the apnoeic periods of the periodic breathing commonly encountered at altitude. The dosage of acetazolamide in these trials has commonly been $250 \mathrm{mg}$ given every eight hours, but a more convenient and probably adequate regimen is one $500 \mathrm{mg}$ slow release tablet each day. Acetazolamide is also a mild diuretic and its protective effect may be due also to this fact. Frusemide has been claimed to be an effective prophylactic, ${ }^{15}$ but the evidence is not so good as for acetazolamide and the more powerful diuretics carry the theoretical objection that they may cause haemoconcentration, making thrombotic episodes more likely. Spironolactone is less powerful than is frusemide and is potassium sparing. If the renin aldosterone system is concerned in acute mountain sickness its use would be logical and one uncontrolled trial supported its efficacy, ${ }^{36}$ but more trials are needed before its use can be recommended in place of acetazolamide.

\section{Treatment}

Little active treatment is needed for benign acute mountain sickness. Paracetamol may help the headache, as will voluntary hyperventilation. Sedatives are better avoided since their respiratory depressant effect will make the hypoxia worse during sleep and their effect may be enhanced by reduced metabolism. If people insist on "something to help them sleep" short acting hypnotics, such as temazepam, are preferable and should be used at the lowest dosage.

The treatment of the malignant forms of acute mountain sickness on the other hand is urgent and vital. Evacuation of the patient to a lower altitude is the single most important measure. Descent by even 300-500 m can have a dramatic effect. While evacuation is awaited, other measures which help include administration of oxygen, in as high a concentration as is compatible with supplies, and diuretics. Frusemide or bumetanide in sufficient dosage to produce a diuresis should be used and this may mean very large doses. Morphine has been reported to be successful in pulmonary oedema, though one is naturally cautious in its use because of its depressant effect on respiration. The role of digoxin is also unclear; again, uncontrolled observations credit it with being useful ${ }^{5}$ but it is emphasised that descent to lower altitude must not be delayed while other measures are tried.

Usually, but not invariably, even malignant acute mountain sickness responds rapidly to treatment. Pulmonary oedema may progress to adult respiratory distress syndrome ${ }^{37}$ and the rarer cerebral oedema seems more often to be refractory to treatment, as the article by Dickinson and his coworkers shows. The lesson from their paper is obvious. Heroic "pressing on" in the face of symptoms of acute mountain sickness is very foolish. Himalayan and Andean altitudes must be treated with respect. If this lesson is observed the great mountains can be enjoyed by walkers of all standards who keep within their own limitations.

Division of Anaesthesia
Medical Research Council Clinical Research Centre
Harrow, Middx

\section{References}

${ }^{1}$ Dickinson JG. Terminology and classification of acute mountain sickness. Br Med J 1982;285:720-1.

${ }^{2}$ Hackett PH, Rennie D. Rales, peripheral edema, retinal hemorrhage and acute mountain sickness. Am J Med 1979;67:214-8.

${ }^{3}$ Ravenhill TH. Some experiences of mountain sickness in the Andes. J Trop Med Hyg 1913;16:314-20.

${ }^{4}$ Hackett PH, Rennie D. The incidence, importance, and prophylaxis of acute mountain sickness. Lancet 1976;ii:1149-54.

${ }^{5}$ Menon ND. High-altitude pulmonary edema. A clinical study. $N$ Engl J Med 1965;273:66-73.

${ }^{6}$ Hultgren HN. Marticorena EA. High altitude pulmonary edema. Epidemiologic observations in Peru. Chest 1978;74:372-6. 
${ }^{7}$ Lakshminarayan S, Pierson DJ. Recurrent high altitude pulmonary edema with blunted chemosensitivity. Am Rev Respir Dis 1975;111;869-72.

${ }^{8} \mathrm{Hu}$ S-T, Huang S-Y, Chu S-C, Pa C-F. Chemoreflexive ventilatory response at sea level in subjects with past history of good acclimatization and severe acute mountain sickness. In: Brendel W, Zink RA, eds. High altitude physiology and medicine. New York: Springer Verlag, 1982:28-32.

9 Sutton JR, Bryan AC, Gray GW, et al. Pulmonary gas exchange in acute mountain sickness. Aviat Space Environ Med 1976;47:1032-7.

${ }^{10}$ Hyers TM, Scoggin CH, Will DH, Grover RF, Reeves JT. Accentuated hypoxemia at high altitude in subjects susceptible to high-altitude pulmonary edema. $J$ Appl Physiol: Respir Environ Exercise Physiol 1979;46:41-6.

"Hackett PH, Rennie D, Hofmeister SE, Grover RF, Grover EB, Reeves JT. Fluid retention and relative hypoventilation in acute mountain sickness. Respiration 1982;43:321-9.

${ }^{12}$ Hultgren HN, Grover RE, Hartley LH. Abnormal çirculatory responses to high altitude in subjects with a previous history of high altitude pulmonary edema. Circulation 1971;44:759-70.

${ }^{13}$ Milledge JS, Catley DM. Renin, aldosterone, and angiotensin converting enzyme during exercise and acute hypoxia in humans. J Appl Physiol: Respir Environ Exercise Physiol 1982;52:320-3.

${ }^{14}$ Houston CS. Acute pulmonary edema of high altitude. $N$ Engl J Med 1960;263:478-80.

15 Singh I, Khanna PK, Srivastava MC, Lal M, Roy SB, Subramanyam CSV. Acute mountain sickness. $N$ Engl J Med 1969;280:175-84.

${ }^{16}$ Hackett PH, Forsling ML, Milledge J, Rennie D. Release of vasopressin in man at altitude. Horm Metab Res 1978;10:571.

${ }^{17}$ Harber MJ, Williams JD, Morton JJ. Antidiuretic hormone excretion at high altitude. Aviat Space Environ Med 1981;52:38-40.

${ }^{18}$ Williams ES, Ward MP, Milledge JS, Withey WR, Older MWJ, Forsling ML. Effect of the exercise of seven consecutive days hill-walking on fluid homeostasis. Clin Sci 1979;56:305-16.

${ }^{19}$ Milledge JS, Bryson EI, Catley DM, et al. Sodium balance, fluid homeostasis and the renin-aldosterone system during the prolonged exercise of hill walking. Clin Sci 1982;62:595-604.

${ }^{20}$ Milledge JS, Catley DM, Williams ES, Withey WR, Mindy BD. Effect of prolonged exercise at altitude on the renin-aldosterone system. J Appl Physiol: Respir Environ Exercise Physiol 1983;55: (in press).
${ }^{21}$ Leuenberger PJ, Stalcup SA, Mellins RB, Greenbaum LM, Turino GM. Decrease in angiotensin I conversion by acute hypoxia in dogs. Proc Soc Exp Biol Med 1978;158:586-9.

${ }^{22}$ Penaloza D, Sime F. Circulatory dynamics during high altitude pulmonary edema. Am J Cardiol 1969; 23:369-78.

${ }^{23}$ Roy SB, Guleria JS, Khanna PK, Manchanda SC, Pande JN, Subba PS. Haemodynamic studies in high altitude pulmonary oedema. Br Heart J 1969;31:52-8.

${ }^{24}$ Fred HL, Schmidt AM, Bates T, Hecht HH. Acute pulmonary edema of altitude. Clinical and physiologic observations. Circulation 1962;25:929-37.

${ }^{25}$ Hultgren HN, Robison MC, Wuerflein RD. Over perfusion pulmonary edema. Circulation 1966;34, suppl 3:132-3.

${ }^{26}$ Whayne TF, Severinghaus JW. Experimental hypoxic pulmonary edema in the rat. J Appl Physiol 1968;25:729-32.

${ }^{27}$ Pines A. High altitude acclimatization and proteinuria in East Africa. Br J Dis Chest 1978;72:196-8.

${ }^{28}$ Bradwell AR, Delamere JP. The effect of acetazolamide on the proteinuria of altitude. Aviat Space Environ Med 1982;53:40-3.

${ }^{29}$ Singh I, Chohan IS. Blood coagulation changes at high altitude predisposing to pulmonary hypertension. $\mathrm{Br}$ Heart $J$ 1972b;34:611-6.

${ }^{30}$ Heath D, Williams DR. Man at high altitude. 2nd ed. London: Churchill Livingstone, 1981.

${ }^{31}$ Cain SM, Dunn JE. Increase of arterial oxygen tension at altitude by carbonic -anhydrase inhibition. J Appl Physiol 1965;20:882-4.

${ }^{32}$ Forwand SA, Landowne M, Follansbee JN, Hansen JE. Effect of acetazolamide on acute mountain sickness. $N$ Engl J Med 1968;279:839-45.

${ }^{33}$ Birmingham Medical Research Expeditionary Society Mountain Sickness Study Group. Acetazolamide in control of acute mountain sickness. Lancet $1981 ; \mathrm{i}: 180-3$.

${ }^{34}$ Larson EB, Roach RC, Schoene RB, Hornbein TF. Acute mountain sickness and acetazolamide. Clinical efficacy and effect on ventilation. JAMA 1982; 248:328-32.

${ }^{35}$ Sutton JR, Gray GW, Houston CS, et al. Effects of duration at altitude and acetazolamide on ventilation and oxygenation during sleep. Sleep 1980;3:455-64.

${ }^{36}$ Currie TT, Carter PH, Champion WL, et al. Spironolactone and acute mountain sickness. Med J Aust 1976;ii:168-70.

${ }^{37}$ Zimmerman GA, Crapo RO. Adult respiratory distress syndrome secondary to high altitude pulmonary edema. West J Med 1980;133:335-7. 